Check for updates

Cite this: Mater. Adv., 2021, 2, 2055

Received 23rd November 2020 Accepted 10th February 2021

DOI: $10.1039 / \mathrm{d} 0 \mathrm{ma} 00915 f$

rsc.li/materials-advances

\title{
Wide optical gap B-doped nc-Si thin films with advanced crystallinity and conductivity on transparent flexible substrates for potential low-cost flexible electronics including $\mathrm{nc}-\mathrm{Si}$ superstrate $\mathrm{p}-\mathrm{i}-\mathrm{n}$ solar cells
}

\author{
Debajyoti Das (D) * and Chandralina Patra
}

\begin{abstract}
The current boost in flexible energy harvesting devices demands the fabrication of solar cells on non-rigid, light-weight and cheap substrates to make roll-to-roll processing technology economically viable. Thus, herein, B-doped nc-Si films possessing $\sim 82.5 \%$ crystallinity with an average grain size of $\sim 9.63 \mathrm{~nm}$, optical band gap of $\sim 1.836 \mathrm{eV}$ and electrical conductivity of $\sim 2.02 \mathrm{~S} \mathrm{~cm}^{-1}$ were grown from $\mathrm{SiH}_{4}$ without deliberate $\mathrm{H}_{2}$ dilution on optically transparent flexible PET substrates at around $30-100{ }^{\circ} \mathrm{C}$. This process was facilitated by the inherent high electron density of the low-pressure plasma in the inductively coupled (ICP) plasma-CVD and strain-induced nanocrystallization process at the incubation layer, originating from substrate surface bending via plasma heating. It was observed that better compliance was achieved on the flexible PET substrate due to its surface deformation, which provided efficient intrinsic stress relaxation during the growth of the film network via energy transfer across the film-substrate interface, triggering prompt crystallization in the film network at a relatively low growth temperature compared to that on the glass substrate. Thus, these films are significant due to their suitable characteristics for the fabrication of low-cost flexible electronics and exclusively for use as window layers in nc-Si superstrate $\mathrm{p}-\mathrm{i}-\mathrm{n}$ solar cells even at ambient temperature.
\end{abstract}

\section{Introduction}

Crystalline silicon wafers and transparent glasses are two commonly used rigid substrates for the fabrication of conventional devices. Currently, the production of flexible devices on plastic substrates is of significant interest because of their advantages in assembling, role-to-role industrial manufacturing, convenience in transportation, and above all, being cost-effective. ${ }^{1-6}$ However, the lower melting point of plastic substrates limits their compatibility in producing device-grade semiconductor nanostructures possessing good opto-electronic properties and stability, causing state-of-the-art device manufacturing to be challenging, in general. ${ }^{7-9}$

Silicon is the backbone of semiconductor engineering; however, within the family of Si species, nanocrystalline silicon (nc-Si) is a unique two-phase photovoltaic material, accommodating high carrier-mobility, better dopability and significantly reduced lightinduced degradation compared to its a-Si counterpart, and

Energy Research Unit, School of Materials Sciences, Indian Association for the Cultivation of Science, Jadavpur, Kolkata-700 032, India.E-mail: erdd@iacs.res.in, profdebajyotidas@gmail.com simultaneously providing lower production cost compared to its c-Si counterpart. ${ }^{10,11}$ Combining superior electrical conductivity and wide optical band gap, B-doped nc-Si films are exclusively used as both emitter layers in heterojunction solar cells ${ }^{12}$ and window layers in nc-Si solar cells with the $n-i-p$ structure ${ }^{13}$ and $\mathrm{p}-\mathrm{i}-\mathrm{n}$ superstrate configuration, in particular, by facilitating essential lattice matching at the intrinsic nc-Si interface, besides their many other applications in flexible electronics. ${ }^{14,15}$

The current boost in flexible energy harvesting devices demands the fabrication of solar cells on non-rigid, light-weight, and cheap substrates, e.g., different polymers such as PET, PEN, and PI films and various cellulose papers, including photo-paper (PP). ${ }^{16-18}$ For the fabrication of flexible solar cells, the low temperature growth of nc-Si films via MOS technology compatible plasma processing is essentially pursued using high $\mathrm{H}_{2}$ dilution to $\mathrm{SiH}_{n}$ precursors or applying high electrical power and/or substrate bias. However, elevated $\mathrm{H}_{2}$ dilution adversely reduces the growth rate, resulting in an increase in the device fabrication cost, and high electrical power and/or substrate bias causes damage on the front face of the substrate and affects the substrate-film interface, which are particularly harmful for films grown on flexible substrates. ${ }^{19-22}$ 
In the present work, B-doped (p-type) nc-Si films delivering significant crystallinity, superior electrical conductivity and a wide optical band gap were developed at around $30-100{ }^{\circ} \mathrm{C}$ on optically transparent and physically flexible substrates, which are compatible for the manufacturing of nc-Si superstrate $\mathrm{p}-\mathrm{i}-\mathrm{n}$ solar cells. Single-step processing in spontaneous RF-plasma (13.56 MHz) of $\mathrm{SiH}_{4}$, without deliberate $\mathrm{H}_{2}$ dilution, was employed at a low pressure $(\sim$ mTorr $)$ in planar inductively coupled plasma (ICP) CVD, with its inherent high electron density retaining an intense atomic $\mathrm{H}$ population at the vicinity of the growth zone. ${ }^{23}$

\section{Experimental}

Using only $2 \mathrm{sccm} \mathrm{SiH}_{4}$ and $10 \mathrm{sccm} \mathrm{B}_{2} \mathrm{H}_{6}\left(1 \%\right.$ in $\left.\mathrm{H}_{2}\right)$ gases in a 13.56 MHz RF-powered planar ICP-CVD reactor maintained at 40 mTorr, B-doped nc-Si thin films were deposited on Corning Eagle $2000^{\mathrm{TM}}$ rigid glass, photo-plate (Kodak Company, USA) and polyethylene terephthalate (PET) (EM6, Garware Polyester Limited, India) polyester-film flexible substrates maintained at a temperature $\left(T_{\mathrm{S}}\right)$ in the range of $30{ }^{\circ} \mathrm{C}(\mathrm{RT})$ to $150{ }^{\circ} \mathrm{C}$. The glass and flexible substrates were cleaned by ultrasonication in ethanol for $10 \mathrm{~min}$, followed by $\mathrm{N}_{2}$ gas blow drying. The thickness of the grown films was measured using a Dektak $6 \mathrm{M}$ stylus profilometer and also via transmission measurements. A Renishaw inVia micro-Raman spectrophotometer was employed for the structural

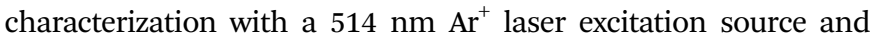
power of $\sim 2 \mathrm{~mW} \mathrm{~cm}^{-2}$ in backscattering geometry. The crystallographic orientations were monitored using a $\mathrm{Cu}-\mathrm{K}_{\alpha} \mathrm{X}$-ray radiation $(\sim 1.5418 \AA)$ source with a Bragg refraction arrangement (Seifert 3000P). Structural studies in terms of the various types of bonding of $\mathrm{Si}$ and $\mathrm{H}$ were performed via Fourier transformed infrared spectroscopy for the films deposited on p-type $\langle 111\rangle \mathrm{c}$-Si polished substrates using a Nicolet Magna-IR 750 FTIR spectrometer. A high-magnification transmission electron microscope (JEOL JSM 2010) functioning at $200 \mathrm{kV}$ was used to obtain the TEM images on $\sim 30 \mathrm{~nm}$ thin films grown on $\mathrm{Cu}$ micro-grids pre-coated by carbon. The surface morphology was studied via field-emission scanning electron microscopy (FE-SEM, JEOLJSM-6700F) and further by atomic force microscopy (AFM; Bruker AXS). The elemental composition (B/Si ratio) of the films was estimated using an Omicron X-ray $(\mathrm{Mg} \mathrm{K} \alpha)$ photoelectron spectrometer. The UV-vis optical data was acquired on a doublebeam spectrophotometer (Hitachi 330). Co-planer parallel Al electrodes with a gap of $1 \mathrm{~mm}$ were deposited on the films by thermal evaporation to measure the dc electrical conductivity in a high vacuum $\left(\sim 5 \times 10^{-5}\right.$ Torr $)$ system and using a Keithley 6517A electrometer.

\section{Results}

The Raman spectra of the p-nc-Si thin-films prepared on Corning Eagle $2000^{\mathrm{TM}}$ glass, polyethylene terephthalate film (PET) and photo-plate (PP) substrates at different temperatures $\left(T_{\mathrm{S}}\right)$, as shown in Fig. 1(a-c), respectively, indicate an analogous asymmetric distribution with a dominant Lorentzian peak at $\sim 520 \mathrm{~cm}^{-1}$, which is related to the transverse optical (TO) vibration mode of c-Si. The spectral line width gradually broadened, accompanied by a red-shift in the peak with a decrease in $T_{\mathrm{S}}$, which may occur due to the miniaturization of the nanocrystals or via strain relaxation at the network. However, the dominant Gaussian component peak at $480 \mathrm{~cm}^{-1}$ in the case of the photo-plate substrate demonstrates the substantial presence of an a-Si fraction in the network, which gradually increased at a lower $T_{\mathrm{S}}$. Considering the ultra-nanocrystalline $\mathrm{Si}$ (size of nanocrystals $<3 \mathrm{~nm}$ ) component peak at $510 \mathrm{~cm}^{-1}$ as part of the network crystallinity, the proportional strength of crystalline volume fraction $\left(\chi_{\mathrm{C}}\right)$ in each case was assessed via the conventional procedure previously reported as follows: ${ }^{24}$

$$
\chi_{\mathrm{C}}=\frac{I_{\mathrm{nc}-\mathrm{Si}}+I_{\mathrm{unc}-\mathrm{Si}}}{I_{\mathrm{nc}-\mathrm{Si}}+I_{\mathrm{unc}-\mathrm{Si}}+I_{\mathrm{a}-\mathrm{Si}}}
$$

where, $I_{x}$ stands for the integrated area under each satellite component $x$ in the corresponding deconvoluted spectrum, as shown in the typical deconvolution in Fig. 1(d).

As plotted in Fig. $1(\mathrm{e})$, the network crystallinity $\left(\chi_{\mathrm{C}}\right)$ of the B-doped nc-Si films on the PP substrate was found to be the lowest, which was only $80.2 \%$ at $T_{\mathrm{S}}=150{ }^{\circ} \mathrm{C}$, and further reduced very fast at a lower $T_{\mathrm{S}}$, attaining $\sim 69.1 \%$ at $T_{\mathrm{S}}=30{ }^{\circ} \mathrm{C}$, whereas it reduced only marginally in the other two cases. On the glass substrate, the crystallinity $\left(\chi_{\mathrm{C}}\right)$ of the p-nc-Si films reduced from $82.2 \%$ to $78.9 \%$, and interestingly, that on the PET substrates was marginally higher and reduced from $\sim 83.6 \%$ to only $80 \%$ with a decrease in $T_{\mathrm{S}}$ from $150{ }^{\circ} \mathrm{C}$ to $30{ }^{\circ} \mathrm{C}$. The nanocrystalline size $\left(D_{\text {Raman }}\right)$ was evaluated from the shift in nc-Si peak using the standard process ${ }^{23}$ as follows:

$$
D_{\text {Raman }}=2 \pi \sqrt{\frac{\beta}{\Delta \omega}}
$$
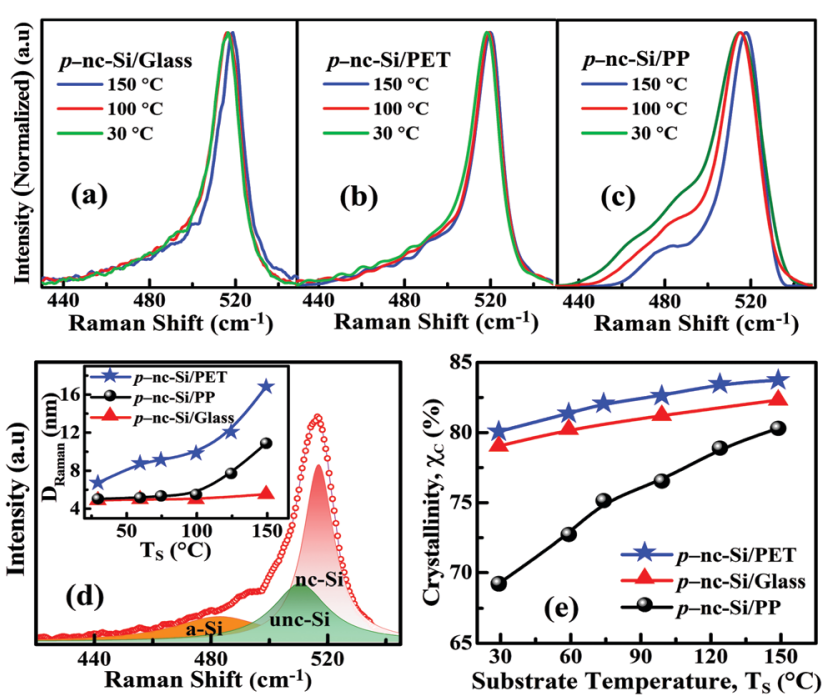

Fig. 1 Raman spectra of p-nc-Si:H films grown at different substrate temperatures $\left(T_{S}\right)$ on (a) glass, (b) polyester film (PET) and (c) photo-plate (PP) substrates. (d) Typical deconvolution of Raman spectrum. Inset: Substrate-dependent variation of grain size $\left(D_{\text {Raman }}\right)$ with $T_{\mathrm{S}}$. (e) Variation in crystallinity $\left(\chi_{c}\right)$ on the different substrates with $T_{S}$. 
where $\Delta \omega$ represents the nc-Si peak shift with reference to the c-Si peak located at $520.8 \mathrm{~cm}^{-1}$ and $\beta=2 \mathrm{~nm}^{2} \mathrm{~cm}^{-1}$. On the flexible substrates, in general, the nanocrystals possessed a larger size of $\sim 16.7 \mathrm{~nm}$ on PET at $T_{\mathrm{S}}=150^{\circ} \mathrm{C}$ [inset of Fig. 1(d)], which reduced sharply to $9.6 \mathrm{~nm}$ at a lower $T_{\mathrm{S}}$ of $\sim 100{ }^{\circ} \mathrm{C}$ and further to $6.5 \mathrm{~nm}$ at $T_{\mathrm{S}}=30^{\circ} \mathrm{C}$. However, on the photographic plate the nanocrystals attained a virtual saturation in size of $\sim 5 \pm 0.2 \mathrm{~nm}$ at $T_{\mathrm{S}} \leq$ $100{ }^{\circ} \mathrm{C}$, whereas on the glass substrate it remained virtually unchanged at $\sim 5 \pm 0.3 \mathrm{~nm}$ over the entire temperature range of $30 \leq T_{\mathrm{S}}\left({ }^{\circ} \mathrm{C}\right) \leq 150$. Apart from the changes in grain size, a shift in the Raman peak occurred via the generation of stress within the network, ${ }^{25,26}$ which may be the reason for obtaining a significant increase in size for the nanocrystals on the flexible substrates, particularly at $T_{\mathrm{S}}>100{ }^{\circ} \mathrm{C}$, given that mechanical deformation seems more feasible than on glass, and also due to the increased incorporation of dopants at elevated $T_{\mathrm{S}} \cdot{ }^{27}$

The XRD spectra shown in Fig. 2(a) for the samples on glass substrates indicate the presence of the $\langle 111\rangle,\langle 220\rangle$ and $\langle 311\rangle$ planes of c-Si, corresponding to the sharp peaks at $2 \theta \sim 28.3^{\circ}$, $47.2^{\circ}$ and $57.2^{\circ}$, respectively, demonstrating the good crystallinity of the network grown even at a low $T_{\mathrm{S}}=60^{\circ} \mathrm{C}$. For the PET substrate, the XRD peak at around $2 \theta \sim 27^{\circ}$ was so intense that the other two peaks at $\sim 47^{\circ}$ and $55^{\circ}$ were faint [Fig. 2(b)]. However, careful analysis via subtraction of the zoomed-in spectrum of the virgin substrate [Fig. 2(c)] from sample-onsubstrate data [Fig. 2(d)] clearly identified, as shown in Fig. 2(e), the presence of a sharp $\langle 220\rangle$ diffraction peak of Si nanocrystallites on the flexible PET substrate ${ }^{28,29}$ which was generated via thermodynamically favoured growth. ${ }^{22,30}$ For the PP substrate, the sample signature could not been separated because of the very high intrinsic XRD response of the substrate itself. The average size $\left(D_{\mathrm{XRD}}\right)$ of the nanocrystals corresponding to each crystallographic orientation was estimated from the FWHM $(\beta)$ of the XRD peaks using the Scherrer equation ${ }^{23}$

$$
D_{\mathrm{XRD}}=0.9 \lambda / \beta \cos \theta
$$

and plotted in Fig. 2(f) together with $D_{\text {Raman }}$ as a function of growth temperature. The crystallite size estimated from the Raman data, $D_{\text {Raman, }}$ presents the average size of the crystals of different orientations, which closely matches with that of the $\langle 220\rangle D_{\mathrm{XRD}}$ and $\langle 311\rangle D_{\mathrm{XRD}}$ data. However, $\langle 111\rangle D_{\mathrm{XRD}}$ appears larger in magnitude. A similar deviation from the Raman data and TEM estimation was also evident in an earlier report, particularly for growth temperatures $\left(T_{\mathrm{S}}\right) \leq 200{ }^{\circ} \mathrm{C} .{ }^{31}$

In general, it was reported in earlier works ${ }^{32-35}$ that depending on the changes in different parameters when the grain size reduces, the crystalline volume fraction in the network deteriorates. However, it was also demonstrated for the Si-nc growth in the nc-Si/a-SiC and nc-Si/a-SiO ${ }_{x}$ mixed phase network ${ }^{30,32,36}$ that despite the reduction in grain size, the crystallinity could improve via a rapid increase in the number of even smaller crystallites. In the present case, on gradually lowering the growth temperature, the crystalline volume fraction of the p-nc-Si network reduced systematically; however, the nature of the changes seemed to grossly vary depending on the characteristics of the substrate materials. In addition, comparing the data relating to the changes
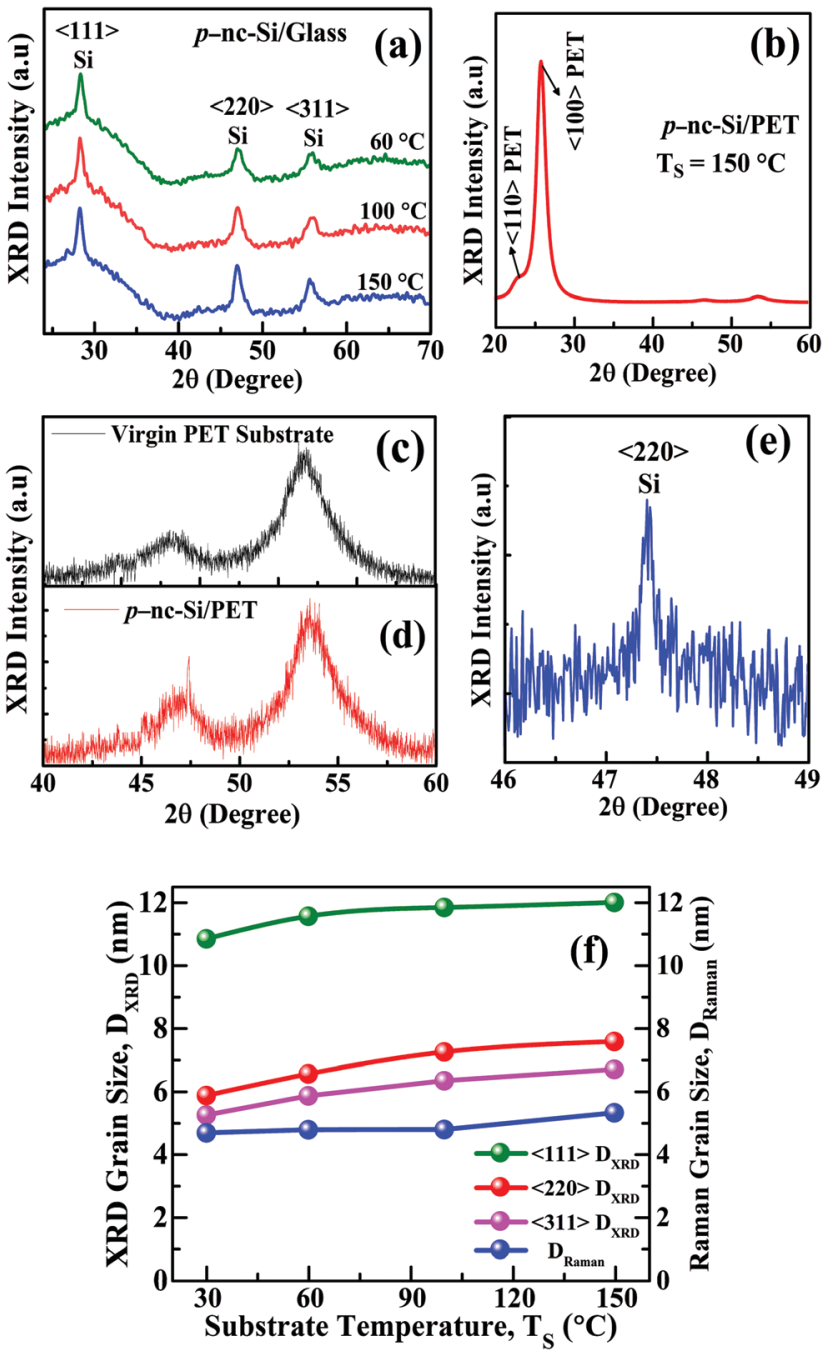

Fig. 2 XRD spectra of $\mathrm{p}-\mathrm{nc}-\mathrm{Si}$ thin film on (a) glass and (b) PET substrate. Zoomed-in spectrum of (c) virgin PET substrate and (d) nc-Si film on PET substrate. (e) Intensity difference of XRD signal, identifying the presence of the $\langle 220\rangle \mathrm{nc}-\mathrm{Si}$ peak as the sample response, removing the substrate effect. (f) Variation in the size $\left(D_{\mathrm{XRD}}\right)$ of the nanocrystalline grains of different crystallographic orientations with $T_{\mathrm{S}}$ and its comparison with that ( $D_{\text {Raman }}$ ) estimated from the Raman data for the $\mathrm{p}$-nc-Si films deposited on glass substrates.

in crystalline volume fraction in Fig. 1(e) and the corresponding grain size in the inset in Fig. 1(d), it is apparent that the number density of crystallites are, in general, lower on the flexible photoplate substrates than that on glass, which further reduced very quickly at $T_{\mathrm{S}}<75{ }^{\circ} \mathrm{C}$, overall revealing the inferior crystallinity in the p-nc-Si network compared to that on the glass substrates. In contrast, superior crystallinity was attained in the p-nc-Si network grown on PET substrates by virtue of the larger size of the nanocrystallites together with their non-diminishing density with a decrease in the growth temperature.

The changes in the chemical structure of the films in terms of different $\mathrm{Si}-\mathrm{H}$ bonding configurations and the amount of bonded $\mathrm{H}\left(C_{\mathrm{H}}\right)$ in the film network were investigated via infrared vibrational studies on the films deposited on p-type 

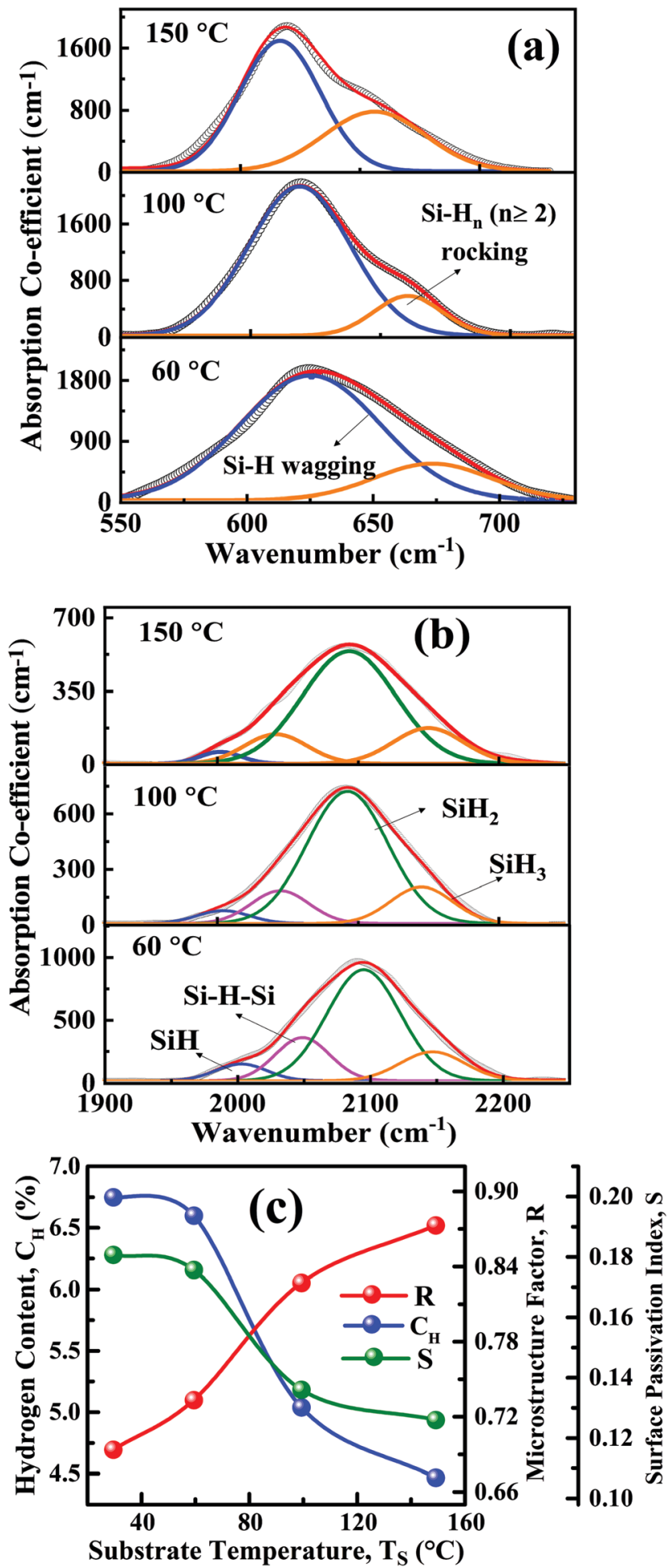

Fig. 3 IR absorption spectra in (a) wagging mode vibration with $\mathrm{Si}-\mathrm{H}$ wagging and $\mathrm{Si}-\mathrm{H}_{n}(n \geq 2)$ rocking components and (b) Si-H stretching mode vibration with different $\mathrm{SiH}_{n}(n=1,2$, and 3) components including $\mathrm{Si}-\mathrm{H}-\mathrm{Si}$ platelet-like component. (c) Variations in the bonded hydrogen content $\left(C_{\mathrm{H}}\right)$, microstructure factor $(R)$ and the surface passivation index (S) with growth temperature $\left(T_{S}\right)$ of the doped nc-Si films.

〈111 c-Si substrates. Fig. 3(a) and (b) present the Si-H wagging and $\mathrm{Si}-\mathrm{H}$ stretching vibration modes of the films prepared at different $T_{\mathrm{S}}$, together with their deconvolutions into various satellite components of $\mathrm{Si}-\mathrm{H}$ wagging and rocking modes, their mono-, di- and tri-hydride stretching modes, and the $\mathrm{Si}-\mathrm{H}-\mathrm{Si}$ platelet-like configurations present in the matrix, respectively. The amounts of bonded $\mathrm{H}\left(C_{\mathrm{H}}\right)$ in the films were estimated using the following equation: ${ }^{37,38}$

$$
C_{\mathrm{H}}=\left(A_{\omega} / N_{\mathrm{Si}}\right) \int \frac{\alpha}{\omega} \mathrm{d} \omega \times 100 \text { at. } \%
$$

where $N_{\mathrm{Si}}=5 \times 10^{22} \mathrm{~cm}^{-3}$ presents the atomic density of c-Si, $A_{\omega}=1.6 \times 10^{19} \mathrm{~cm}^{-2}$ is the oscillator strength and $\int \frac{\alpha}{\omega} \mathrm{d} \omega$ corresponds to the integrated absorption by the $\mathrm{Si}-\mathrm{H}$ wagging mode component at around $620 \mathrm{~cm}^{-1}$.

Furthermore, according to the deconvoluted stretching mode absorption components, the microstructure factor $(R)$, which is related to the poly-hydride fraction of the network,

$$
R=\left(I_{\mathrm{SiH} 3}+I_{\mathrm{SiH} 2}\right) /\left(I_{\mathrm{SiH} 3}+I_{\mathrm{SiH} 2}+I_{\mathrm{SiH}}+I_{\mathrm{Si}-\mathrm{H}-\mathrm{Si}}\right)
$$

and the surface passivation index $(S)$, identified by the $\mathrm{Si}-\mathrm{H}-\mathrm{Si}$ platelet-like component present in the matrix, ${ }^{38,39}$

$$
S=I_{\mathrm{Si}-\mathrm{H}-\mathrm{Si}} /\left(I_{\mathrm{SiH} 3}+I_{\mathrm{SiH} 2}+I_{\mathrm{SiH}}+I_{\mathrm{Si}-\mathrm{H}-\mathrm{Si}}\right)
$$

were estimated, where $I_{x}$ corresponds to the integrated absorption under each satellite component $\mathrm{SiH}_{3}, \mathrm{SiH}_{2}, \mathrm{SiH}$ and $\mathrm{Si}-\mathrm{H}-\mathrm{Si}$, as shown in Fig. 3(b). It was revealed from Fig. 3(c) that $C_{\mathrm{H}}$ reduced from 6.74 at.\% to 4.45 at.\% with an increase in $T_{\mathrm{S}}$ from $30{ }^{\circ} \mathrm{C}$ to $150{ }^{\circ} \mathrm{C}$. The similar reducing nature of the surface passivation index $(S)$ with a low magnitude of $\sim 0.125$ and the concomitant elevation in the microstructure factor $(R)$ to a high magnitude of $\sim 0.87$ both indicate a gradual increase in crystallinity within the Si network at an elevated $T_{\mathrm{S}}$. Significantly high crystallinity in the film network was obtained on the c-Si substrate at $T_{\mathrm{S}}=150{ }^{\circ} \mathrm{C}$, which was also obtained on all the other substrates, as shown in Fig. 1(c). Furthermore, it was noted that sharp changes in all the parameters, e.g., $C_{\mathrm{H}}, S$ and $R$, occurred most prominently within the temperature range of $60-100{ }^{\circ} \mathrm{C}$, where a transition in the rate of change in crystallinity of the $\mathrm{Si}: \mathrm{H}$ network, particularly on the photo-plate substrate, was demonstrated in Fig. 1(d).

The SEM images of the B-doped nc-Si films grown at the highest $T_{\mathrm{S}}$ of $\sim 150{ }^{\circ} \mathrm{C}$ on the glass and PET substrates, as shown in Fig. 4(a) and (b), respectively, demonstrate that on glass the sample has a compact and granular structure with a homogeneous surface distribution of tiny and unique size grains with sharp grain boundaries. In contrast, on PET, the sample surface possesses an inhomogeneous morphology, comprised of a variety of larger-sized clusters (as identified by the areas enclosed by white borders) and irregular cracks with black lines of wide separations. ${ }^{40}$ In general, a larger average size $(\sim 16.7 \mathrm{~nm})$ of the grains on the PET substrate compared to that $(\sim 5.3 \mathrm{~nm})$ on the glass substrate was also determined using the Raman data [Fig. 1(d)]. However, for the sample grown on PET at $100{ }^{\circ} \mathrm{C}$ [Fig. 4(c)] its cluster size was smaller and its cracks were narrower.

The atomic force microscopy images of the B-doped nc-Si films grown on glass and PET substrates at different temperatures are 

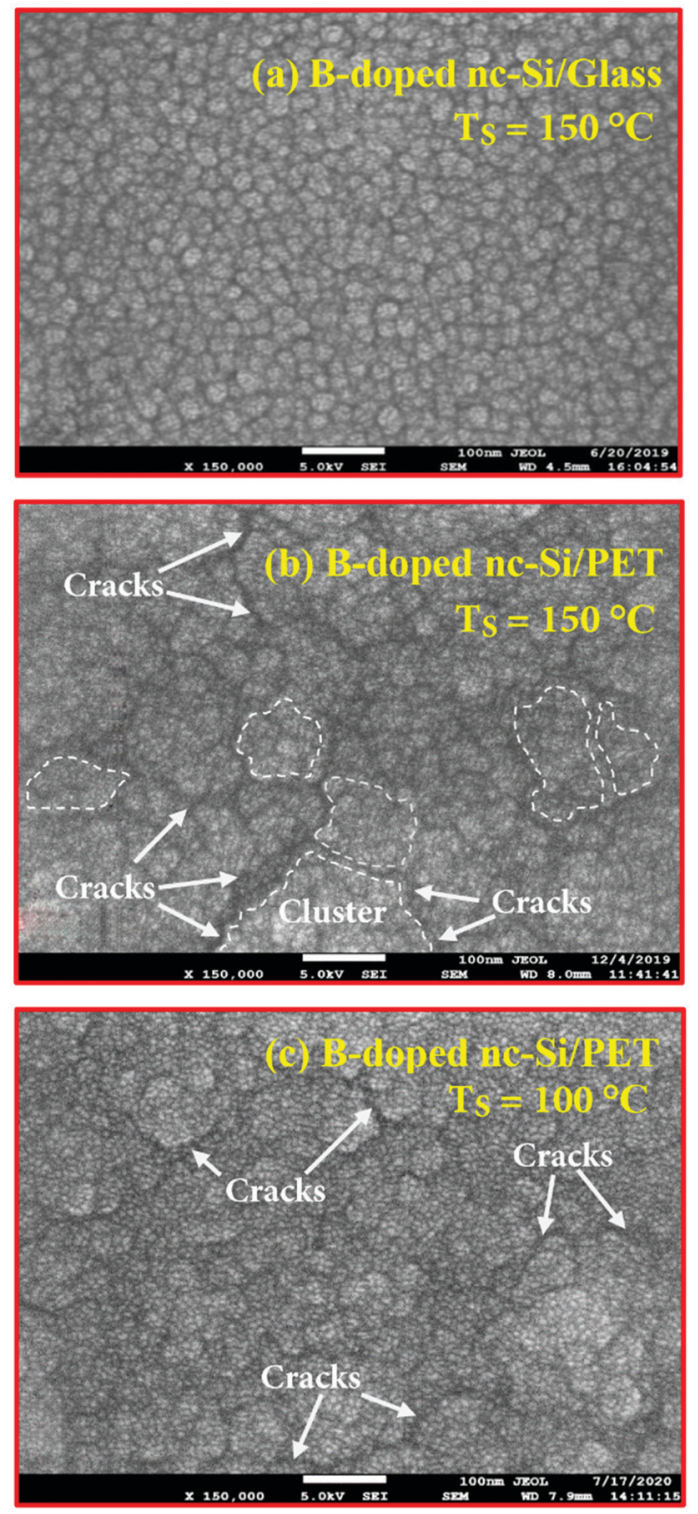

Fig. 4 SEM images of $\mathrm{p}-\mathrm{nc}$-Si films on (a) glass, $T_{\mathrm{S}}=150^{\circ} \mathrm{C}$, and on PET substrate at (b) $T_{\mathrm{S}}=150{ }^{\circ} \mathrm{C}$ and (c) $T_{\mathrm{S}}=100{ }^{\circ} \mathrm{C}$.

shown in Fig. 5(a) and (b), respectively. For each type of substrate, the surface of the film deposited at a low temperature $\left(30{ }^{\circ} \mathrm{C}\right)$ seemed to possess an inhomogeneous texture containing numerous voids, and consequently a relatively high surface roughness. The void density and the surface inhomogeneity sharply reduced at an elevated $T_{\mathrm{S}}$. Comparing the individual effects induced by the nature of the substrate and according to its consistently lower average surface roughness, as shown in Fig. 5(c), it seemed that the PET substrate facilitated better coalescence of the material, and hence an increase in overall crystallinity in the p-nc-Si network, as also evident from the Raman studies [Fig. 1(e)]. A similar observation was reported earlier ${ }^{41}$ in both AFM and Raman studies that second to the c-Si wafer substrate, the PET substrate propagates an improved crystalline network in the film than on glass substrate. However, with a further increase in $T_{\mathrm{S}} \sim$ $150{ }^{\circ} \mathrm{C}$, the relatively higher surface roughness is consistent with the formation of surface cracks on the sample on the PET substrate, as evident from the SEM data in Fig. 4(b).

The TEM images of the samples prepared on C-coated $\mathrm{Cu}$-microgrids at two different $T_{\mathrm{S}}, \sim 30{ }^{\circ} \mathrm{C}$ and $100{ }^{\circ} \mathrm{C}$, are represented in Fig. 6(a) and (b), respectively. At the lowest $T_{\mathrm{S}}$ of $\sim 30{ }^{\circ} \mathrm{C}$, the TEM image reveals the dispersion of tiny crystallites within the amorphous network, as shown in Fig. 6(a-i). In the high-resolution image shown in Fig. 6(a-ii), individual nanocrystals containing distinctly separated lattice planes corresponding to the $\langle 111\rangle$ and $\langle 220\rangle$ crystal orientations are evident, which are further supported by the corresponding diffraction pattern in Fig. 6(a-iii). At a moderate $T_{\mathrm{S}}$ of $\sim 100^{\circ} \mathrm{C}$, the TEM micrograph in Fig. 6(b-i) and the high-resolution image in Fig. 6(b-ii) reveal the prominent distribution of high density and comparatively large-size nanocrystallites dispersed in the amorphous matrix. The TED pattern in Fig. 6(b-iii) consists of very bright and sharp circular rings, wherein, in addition to the $\langle 111\rangle$ and $\langle 220\rangle$ planes, $\langle 311\rangle$ nanocrystalline orientations can be distinctly observed, as also shown in Fig. 6(a-iii). ${ }^{23}$

The optical properties of the B-doped nc-Si films grown on transparent rigid glass and flexible PET substrates were studied via UV-vis absorption. Fig. 7(a) represents the transmission spectra of the two films grown at $100{ }^{\circ} \mathrm{C}$ on two transparent substrates, glass and PET. Besides the mechanical measurement using a stylus, the film thickness was also optically assessed from the waves in the transmission spectra using the Swanepoel method. ${ }^{42}$ It is apparent from the spectral distribution that on the same run, the grown films were thicker on the glass than on PET. At $T_{\mathrm{S}}=100{ }^{\circ} \mathrm{C}$, the B-doped nc-Si films grew on glass at a deposition rate of $\sim 14.9 \mathrm{~nm} \mathrm{~min}{ }^{-1}$, while that on PET reduced to $\sim 7.5 \mathrm{~nm} \mathrm{~min}^{-1}$. The optical band gaps were estimated from the intercept of the linear slope of the Tauc plot $(\sqrt{ } \alpha h \nu v s . h \nu)$ to $\alpha=0$ [Fig. 7(b)], following the standard process using the Tauc equation: ${ }^{43,44}$

$$
(\alpha h \nu)^{1 / 2}=B\left(h \nu-E_{g}\right)
$$

where $\alpha$ is the absorption coefficient and $B$ is the Tauc constant.

The slope of the plots, i.e., the Tauc constant $B$, became very different for the p-nc-Si films deposited on the two different types of substrates in the same run, as shown in Fig. 7(b). The magnitude of $B$ was higher in the case of the rigid glass substrate than that of the flexible PET substrate, and the optical band gaps $\left(E_{\mathrm{g}}\right)$ of the p-nc-Si films demonstrated higher magnitudes when deposited on glass. In general, the optical band gap of the B-doped nc-Si films reduced monotonically at a lower $T_{\mathrm{S}}$, as shown in Fig. $7(\mathrm{c})$, for the set of films grown on PET substrates. The slope of the plots, i.e., the Tauc constant $B$, remained very close, identifying a limited change in crystallinity within the range of variation in $T_{\mathrm{S}}, 30-150{ }^{\circ} \mathrm{C}$, wherein the crystalline volume fraction increased from $80 \%$ to $83.6 \%$ only, as estimated from the Raman data. Within the temperature range of $30-150{ }^{\circ} \mathrm{C}$, the $\left(E_{\mathrm{g}}\right)_{\text {Glass }}$ increased from 1.814 to $1.875 \mathrm{eV}$, while the relatively lower $\left(E_{\mathrm{g}}\right)_{\mathrm{PET}}=1.792 \mathrm{eV}$ at $T_{\mathrm{S}}=30^{\circ} \mathrm{C}$ increased to $\sim 1.869 \mathrm{eV}$ at $T_{\mathrm{S}}=150{ }^{\circ} \mathrm{C}$, which was very close to that of the corresponding $\left(E_{\mathrm{g}}\right)_{\text {Glass}}$, as shown in Fig. $7(\mathrm{~d})$. 
(a) $p$-nc-Si/Glass
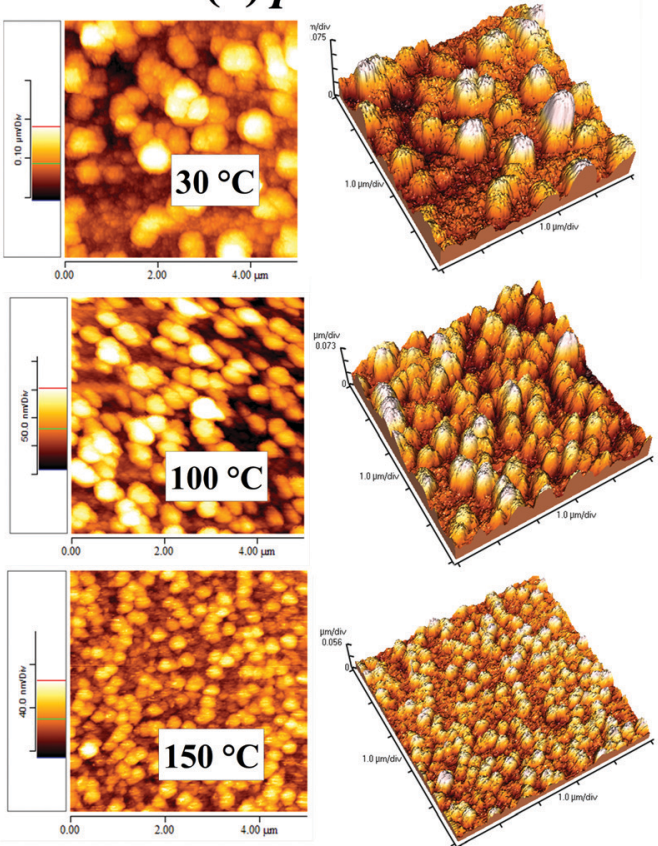

(b) $p$-nc-Si/PET

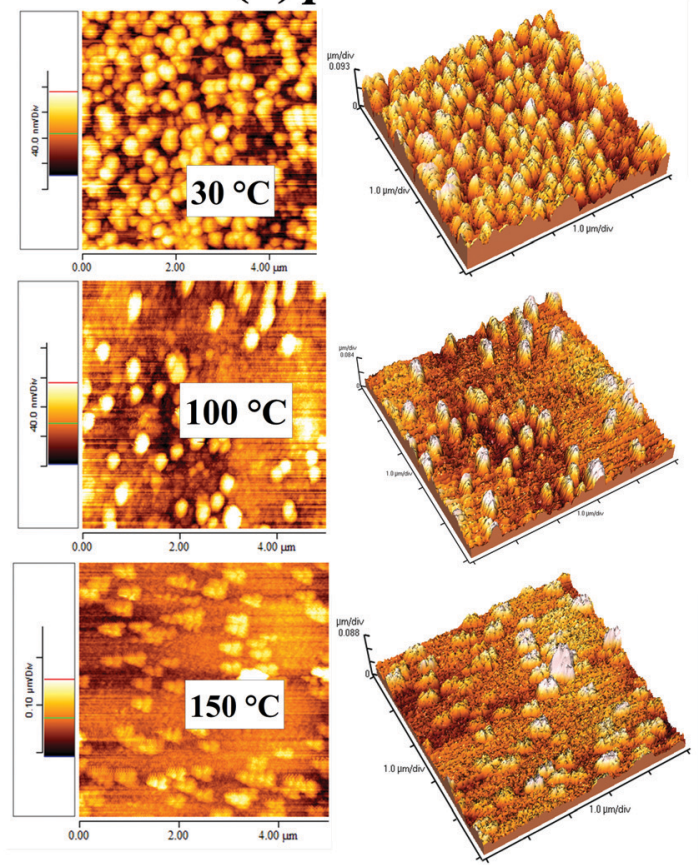

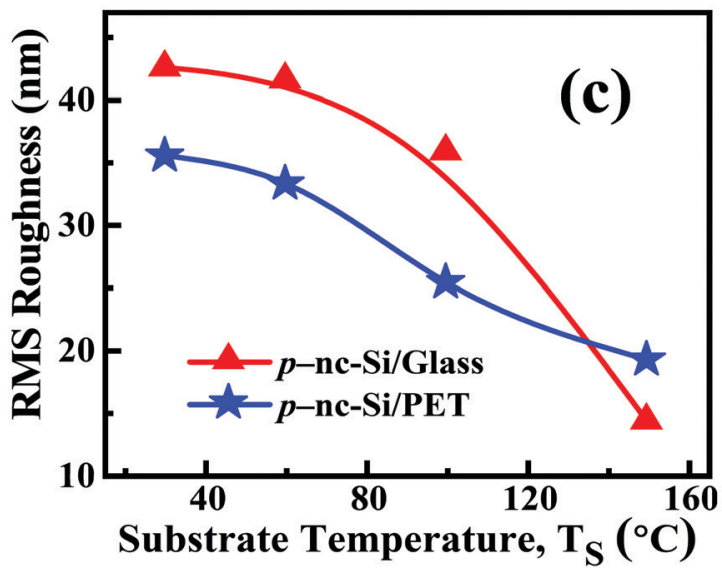

Fig. 5 AFM images with 2D and 3D views of $\mathrm{p}-\mathrm{nc}$-Si films deposited on (a) glass and (b) PET substrates. (c) Comparison of the RMS roughness of the $\mathrm{p}$-nc-Si films on glass and PET substrates at different $T_{\mathrm{S}}$.

The plot of room temperature dark electrical-conductivity $\left(\sigma_{\mathrm{D}}\right)$ as a function of growth temperature $\left(T_{\mathrm{S}}\right)$ in Fig. 8 indicates that $\left(\sigma_{\mathrm{D}}\right)_{\mathrm{Glass}}$ at each temperature had a trivially higher magnitude than $\left(\sigma_{\mathrm{D}}\right)_{\mathrm{PET}}$, together with their similar nature of variation in the range of $30 \leq T_{\mathrm{S}}\left({ }^{\circ} \mathrm{C}\right) \leq 100$, above which, the formation of significant surface cracks on the sample on PET may obstruct the regular $T_{\mathrm{S}}$-induced promotion of electrical transport, leading to a relatively larger difference in $\sigma_{\mathrm{D}} \cdot{ }^{45}$ Although $\left(\sigma_{\mathrm{D}}\right)_{\mathrm{PP}}$ at $150{ }^{\circ} \mathrm{C}$ was lower than the others, it further reduced by more than two orders of magnitude with a decrease in $T_{\mathrm{S}}$ to $30{ }^{\circ} \mathrm{C}$, with the deterioration being faster at $T_{\mathrm{S}}$ below $75{ }^{\circ} \mathrm{C}$. The B-doped nc-Si films having $\left[\left(\sigma_{\mathrm{D}}\right)_{\mathrm{PET}}\right]_{30^{\circ} \mathrm{C}} \sim 0.61 \mathrm{~S} \mathrm{~cm}^{-1}$ and $\left[\left(\sigma_{\mathrm{D}}\right)_{\mathrm{PET}}\right]_{100^{\circ} \mathrm{C}} \sim 2.02 \mathrm{~S} \mathrm{~cm}^{-1}$, with the corresponding $\left[\left(E_{\mathrm{g}}\right)_{\mathrm{PET}}\right]_{30^{\circ} \mathrm{C}} \sim 1.792 \mathrm{eV}$ and $\left[\left(E_{\mathrm{g}}\right)_{\mathrm{PET}}\right]_{100^{\circ} \mathrm{C}} \sim$ $1.836 \mathrm{eV}$, and simultaneous crystallinity $\left[\left(\chi_{\mathrm{C}}\right)_{\mathrm{PET}}\right]_{30}{ }^{\circ} \mathrm{C} \sim 80 \%$ and $\left[\left(\chi_{\mathrm{C}}\right)_{\mathrm{PET}}\right]_{100^{\circ} \mathrm{C}} \sim 82.5 \%$, seem very attractive materials for application in solar cells with a tandem structure and flexible electronic devices using transparent PET substrates.

Fig. 9(a) and (b) present the typical wide-scan XPS spectra of the B-doped nc-Si films grown on the flexible PET and rigid glass substrates, revealing distinct peaks of Si-2p and Si-2s at $\sim 100 \mathrm{eV}$ and $150 \mathrm{eV}$, respectively, and a relatively weak peak at $\sim 187 \mathrm{eV}$, which corresponds to the B-1s component, representing its presence in a very small percentage as the dopant in the network. ${ }^{46}$ According to the B-1s peak, the individual contribution of the B-Si component was separated via spectral deconvolution, eliminating the impact of the plasmonic component, as shown in the insets in Fig. 9(a) and (b). ${ }^{23,47}$ The content of B in the doped nc-Si films was estimated from the ratio of integrated area under the B-Si peak with the combination of integrated areas under all the Si-peaks, e.g., Si-2p and Si-2s. Based on this 

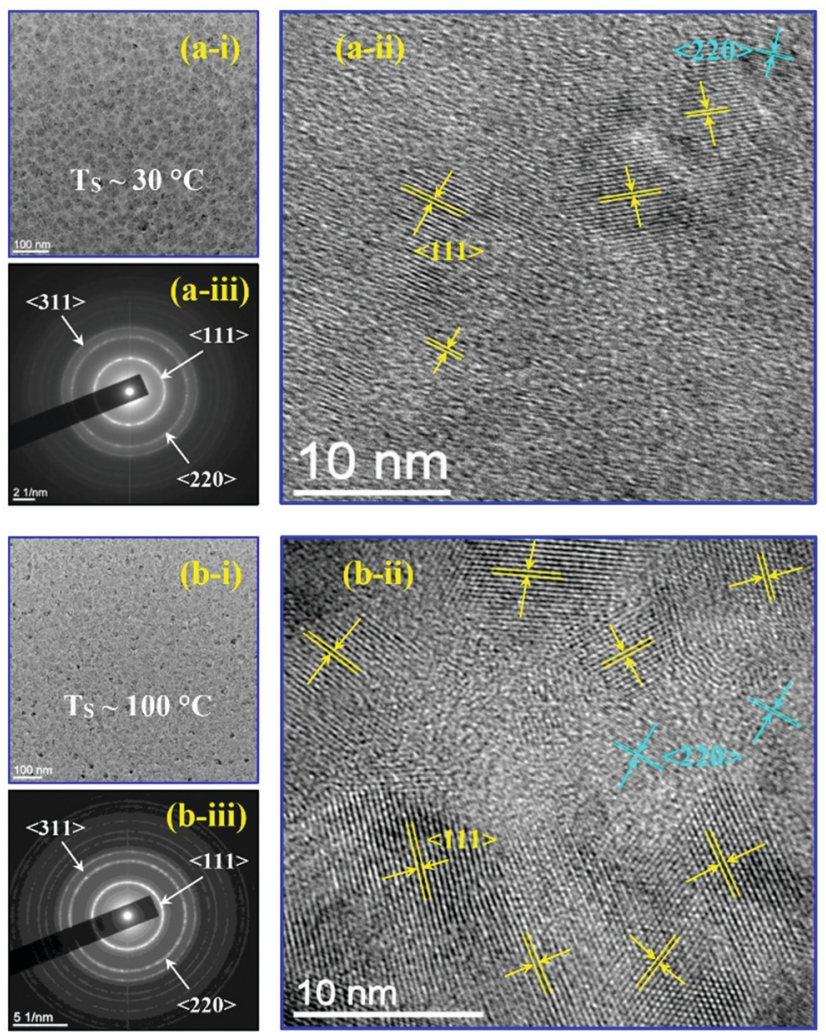

Fig. 6 TEM images of $\mathrm{p}$-nc-Si films grown at (a) $T_{\mathrm{S}}$ of $\sim 30{ }^{\circ} \mathrm{C}$ and (b) $100{ }^{\circ} \mathrm{C}$, in (i) moderate and (ii) high-resolution, and the corresponding (iii) SAED patterns.

analysis, the B concentration was estimated to be around 2.99, 3.25 and 3.45 at.\% on the PET substrate, and 3.2, 3.55 and 3.95 at.\% on the glass substrate for the samples prepared at $T_{\mathrm{S}}=30{ }^{\circ} \mathrm{C}$, $100{ }^{\circ} \mathrm{C}$ and $150{ }^{\circ} \mathrm{C}$, respectively, as presented in the bar chart shown in Fig. 9(c).

\section{Discussion}

In general, the photo-plate substrate provided less crystallinity for the nc-Si film, which may be attributed to the very different chemical nature and roughness of the substrate, which control the surface reactions. ${ }^{48}$ The emulsion layer containing silver halide grains dispersed in a gelatin matrix on the photo-plate substrate makes the surface rough, inhomogeneous and unstable, which encourage random growth. At elevated $T_{\mathrm{S}}$, the rapid removal of humidity from the gelatin-latex emulsion layer of the photo-plate surface causes the degree of crystallization, $\left(\chi_{\mathrm{C}}\right)_{\mathrm{PP}}$, to be closer to that of the other substrates, together with a similar elevation in $\left(\sigma_{\mathrm{D}}\right)_{\mathrm{PP}}$. A significantly high $\left(\chi_{\mathrm{C}}\right)_{\text {Glass }}$ of $\sim 78.9 \%$ and remarkable $\left(\sigma_{\mathrm{D}}\right)_{\text {Glass }}$ of $\sim 1 \mathrm{~S} \mathrm{~cm}^{-1}$ for the p-nc-Si film deposited at room temperature $\left(T_{\mathrm{S}}=30{ }^{\circ} \mathrm{C}\right)$ from $\mathrm{SiH}_{4}$ without additional $\mathrm{H}_{2}$ dilution are the result of the unique high electron density $\left(\sim 10^{12} \mathrm{~cm}^{-3}\right)$ plasma of ICP-CVD, which demonstrates a very special route for high yield nanocrystalline growth. ${ }^{24}$
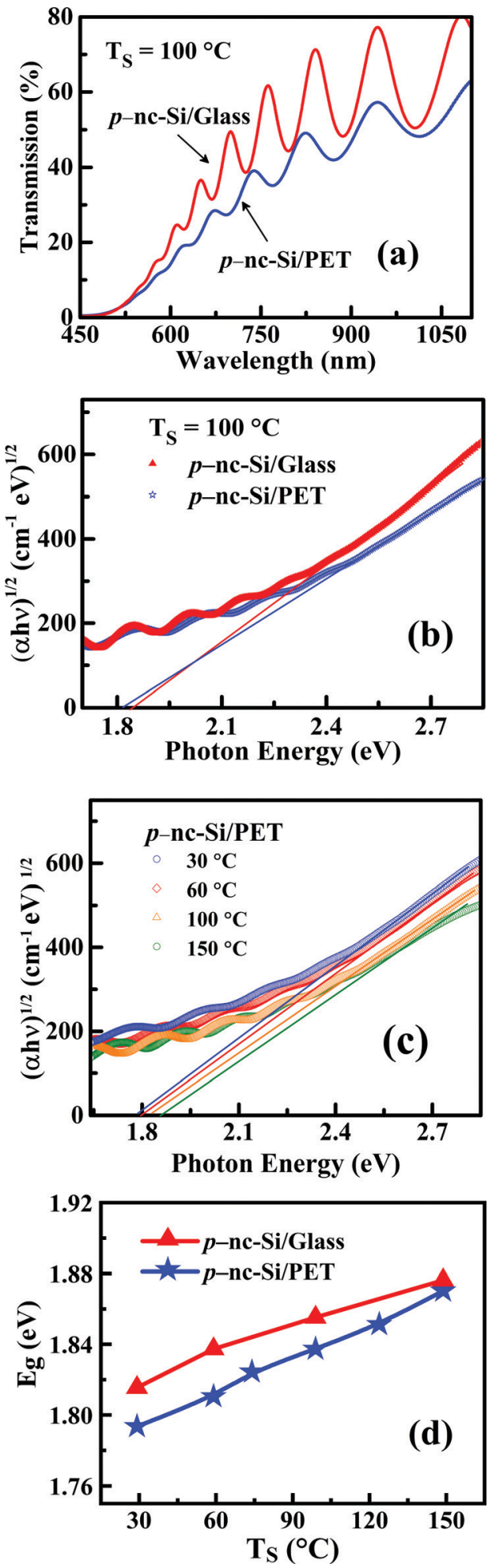

Fig. 7 (a) Transmission spectra of $\mathrm{p}$-nc-Si films grown on glass and PET substrates at $T_{\mathrm{S}}=100{ }^{\circ} \mathrm{C}$ and their (b) absorption data in the Tauc plot. (c) Comparison of the Tauc plots of the $\mathrm{p}$-nc-Si films deposited at different $T_{\mathrm{S}}$ on PET substrates and (d) comparison of the variations in $E_{\mathrm{g}}$ with $T_{\mathrm{S}}$ for the samples on glass and PET substrates.

During nanocrystallization, the formation dynamics of the incubation layer at the substrate surface dominantly controls 


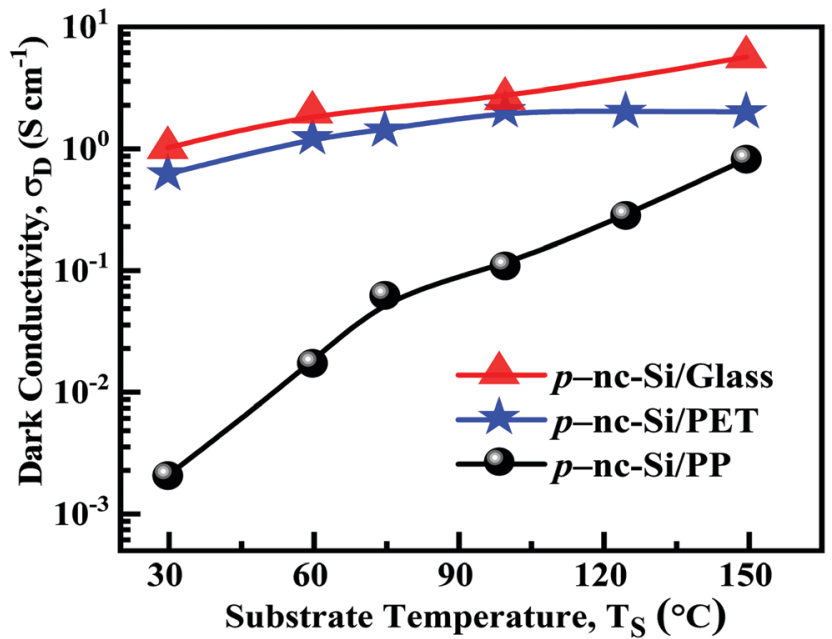

Fig. 8 Comparison of the $T_{\mathrm{S}}$-dependent $\sigma_{\mathrm{D}}$ of the p-nc-Si films grown on glass, photo-plate and PET substrates.

the subsequent growth kinetics, which in turn, sensitively depends on the substrate material and morphology, besides parameters such as temperature and electrical bias. ${ }^{22}$ Undoped poly-Si thin films grown on a PET substrate using $\mathrm{SiH}_{4}$ in $99.5 \%$ $\mathrm{H}_{2}$ dilution in conventional $\mathrm{RF}$ PE-CVD demonstrated the maximum conductivity $\sim 8.4 \times 10^{-5} \mathrm{~S} \mathrm{~cm}^{-1}$, corresponding to the maximum crystallinity of $\sim 71.5 \%$ and narrowest optical band gap of $\sim 1.66 \mathrm{eV}$ at a substrate bias of $-100 \mathrm{~V} \cdot{ }^{40}$ At a very high -ve bias applied to the substrate, the band gap increased significantly due to nanocrystallization in the network, corresponding to a phase transition from high crystallinity towards an amorphous-dominated structure. Using extremely high $\mathrm{H}_{2}$ dilution in the $\mathrm{SiH}_{4}$ plasma in capacitively coupled RF PE-CVD, a crystalline volume fraction of up to $68.8 \%$ was previously reported ${ }^{49}$ for a B-doped nc-Si sample grown on PET substrate at $-120 \mathrm{~V}$ bias, revealing the maximum magnitude of dark conductivity of $\sim 1.94 \mathrm{~S} \mathrm{~cm}^{-1}$. However, a further increase in bias caused high-energy $\mathrm{H}^{+}$ion bombardment and subsequent degradation of the crystallinity. In the doped $\mu \mathrm{c}-\mathrm{Si}: \mathrm{H}$ films deposited at $T_{\mathrm{S}}=100{ }^{\circ} \mathrm{C}$, a higher crystalline volume fraction $\left(\chi_{\mathrm{C}} \sim 68 \%\right)$ on the PET substrate compared to that on glass (only $\sim 22 \%$ ) was reported by Dirani et al. ${ }^{41}$ while $74 \%$ crystallinity was obtained on a single crystal Si substrate. However, their P-doped $\mu \mathrm{c}$-Si:H films prepared from highly $\mathrm{H}_{2}$-diluted $\mathrm{SiH}_{4}$ plasma in RF-PECVD on a PET substrate demonstrated very low dark conductivity, $\sigma_{\mathrm{D}}$, of $\sim 5 \times 10^{-6} \mathrm{~S} \mathrm{~cm}^{-1}$, which was only 2 times higher than that on a glass substrate. In B-doped $\mu \mathrm{c}-\mathrm{Si}$ films deposited by HW-CVD using 93.5\% $\mathrm{H}_{2}$-diluted $\mathrm{SiH}_{4}$, Alpuim et al. ${ }^{50}$ obtained a similar increase in crystalline volume fraction for the samples deposited on PET substrates $\left(\chi_{\mathrm{C}} \sim 72 \%\right)$ compared to that on glass substrates $\left(\chi_{\mathrm{C}} \sim 65 \%\right)$, although the conductivity of the samples on PET $\left(\sigma_{\mathrm{D}} \sim 2.6 \times 10^{-1} \mathrm{~S} \mathrm{~cm}^{-1}\right)$ was lower than that on glass $\left(\sigma_{\mathrm{D}} \sim 8.9 \times 10^{-1} \mathrm{~S} \mathrm{~cm}^{-1}\right)$.

Because of similar reasons in facilitating device fabrication, besides $\mathrm{Si}$ in its different structural configurations, e.g., amorphous, nanocrystalline, microcrystalline and polycrystalline thin films,
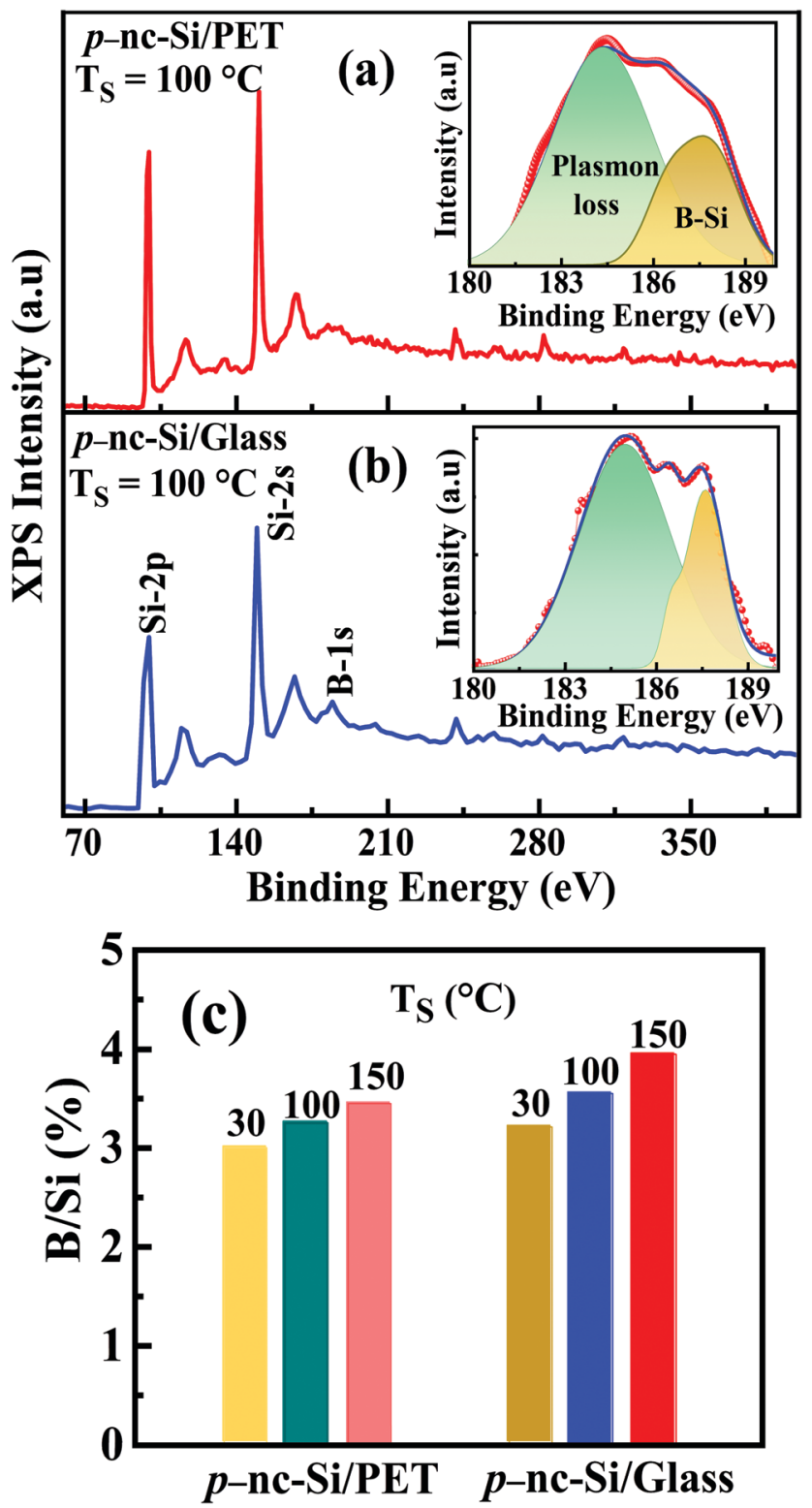

Fig. 9 XPS data of p-nc-Si films on (a) PET and (b) glass substrates, and (c) estimated $\mathrm{B}$ to $\mathrm{Si}$ ratio in the doped $\mathrm{nc}-\mathrm{Si}$ films grown on different substrates and at different $T_{\mathrm{S}}$ presented in a bar chart.

various other semiconductor thin films, e.g., $\mathrm{CdS},{ }^{51} \mathrm{ZnO},{ }^{52,53}$ In-doped $\mathrm{ZnO}(\mathrm{IZO}),{ }^{54} \mathrm{Al}$-doped $\mathrm{ZnO}(\mathrm{AZO}),{ }^{55}$ were deposited simultaneously on flexible PET and rigid glass substrates and studied with their differences in opto-electronic properties. It was identified that, in general, these films possessed higher crystallinity; however, simultaneously narrower optical band gaps and mostly lower electrical conductivity when deposited on PET substrate than on glass substrate.

In the present investigation, the superior crystallinity on the flexible PET substrate originated from the strain-induced crystallization at the incubation layer due to substrate bending via plasma heating. ${ }^{56}$ The stress generated at the substrate/ incubation layer interface provides the activation energy for 
nanocrystallization and favours the formation of larger nanocrystals at elevated $T_{\mathrm{S}}$ and also leads to a gradually increased difference in crystallinity, although trivially, compared to that on glass substrate. ${ }^{57,58}$ Although possessing a higher $\left(\chi_{\mathrm{C}}\right)_{\mathrm{PET}}$ $(\sim 80 \%)$, the $\left(\sigma_{\mathrm{D}}\right)_{\mathrm{PET}}\left(\sim 6.01 \times 10^{-1} \mathrm{~S} \mathrm{~cm}^{-1}\right)$ of the p-nc-Si film prepared at ambient temperature $\left(T_{\mathrm{S}}=30{ }^{\circ} \mathrm{C}\right)$ appeared to be slightly lower than $\left(\sigma_{\mathrm{D}}\right)_{\text {Glass }}\left(\sim 9.95 \times 10^{-1} \mathrm{~S} \mathrm{~cm}^{-1}\right)$ and this deviation increased at $T_{\mathrm{S}}>100{ }^{\circ} \mathrm{C}$, which indicates that the surface strain/bending may not be favorable for electrical transport in samples on flexible PET substrates. This becomes more severe at higher $T_{\mathrm{S}}$ due to the formation of micro-cracks on the sample surface. Although better network ordering corresponding to higher crystallinity resulted in a wider optical band gap $\left(E_{\mathrm{g}}\right)$ in the p-nc-Si films at elevated $T_{\mathrm{S}}$ in the range of 30-150 ${ }^{\circ} \mathrm{C}$ on both the flexible PET and rigid glass substrates, fundamentally $E_{\mathrm{g}}$ always exhibit a lower magnitude in PET than on glass.

Generally, the optical band gap of the Si:H network depends on two major factors, the intrinsic network structure and the bonded $\mathrm{H}$ content $\left(C_{\mathrm{H}}\right)$, including its nature of bonding as mono, di- or poly-hydride. In the case of an Si:H network with moderate crystallinity (containing a significant amount of amorphous component) and lower $\sigma_{\mathrm{D}}$, normally with an increase in the deposition temperature, $C_{\mathrm{H}}$ reduces and the $\mathrm{SiH}_{n}$ bond becomes gradually less poly-hydride in configuration, which together lead to a systematic decrease in the optical band gap. ${ }^{59}$ By scavenging the $\mathrm{H}$ attached to the Si-network via atomic $\mathrm{F}$ and $\mathrm{H}$ together, on the ECR-CVDgrown Si:H films normally possessing a huge hydrogen content, relatively non-rigid network containing a significant amount of voids, and consequently a wide optical gap, it was demonstrated that the optical band gap changed proportionally with the bonded $\mathrm{H}$ content. ${ }^{60}$ Furthermore, in Si:H films possessing a low $\mathrm{H}$ content prepared by repeating growth interruption, and subsequently increasing the dose of $\mathrm{H}$ plasma treatment in both ECR-CVD and capacitively coupled PE-CVD, systematic widening of the optical band gap was obtained by virtue of the gradual increase in poly-hydrogenation of the network and significant network ordering, even with the simultaneous significant elimination of bonded $\mathrm{H}$ from the network. ${ }^{60-62}$ It was reported by Mahan el al. ${ }^{63}$ that the intrinsic optical band gap of the SiH network in medium range order, $\left(E_{\mathrm{g}}\right)_{\mathrm{MRO}}$, follows the empirical relation: $E_{\mathrm{g}}=\left(E_{\mathrm{g}}\right)_{\mathrm{MRO}}+0.0135 C_{\mathrm{H}}$, where $E_{\mathrm{g}}$ is the experimentally determined optical band gap and $C_{\mathrm{H}}$ is the bonded $\mathrm{H}$ content of the network. Furthermore, they demonstrated that the magnitude of $\left(E_{\mathrm{g}}\right)_{\mathrm{MRO}}$ increases linearly with an increase in network ordering. In the case of the present series of B-doped nc-Si films deposited on glass and PET substrates, the amount of $\mathrm{H}$ bonded to the network is very low by virtue of the high crystallinity of the network and simultaneous unavailability of surplus atomic $\mathrm{H}$ in the plasma because of the use $\mathrm{SiH}_{4}$ plasma without deliberate $\mathrm{H}_{2}$ dilution in ICP-CVD. Within this network, the increase in the experimentally determined optical band gap $\left(E_{\mathrm{g}}\right)$ on removal of $\mathrm{H}$ and simultaneous increase in the microstructure factor (R) at an elevated growth temperature $\left(T_{\mathrm{S}}\right)$ [Fig. 3(c)] essentially signify the systematic widening of the intrinsic optical band gap, $\left(E_{\mathrm{g}}\right)_{\mathrm{MRO}}$ or $\left(E_{\mathrm{g}}\right)_{\mathrm{SRO}}$, due to the gradual temperature-mediated improvement in the network towards short-range ordering (SRO). This phenomenon applies equally for films grown on glass and flexible PET substrates, where a virtually identical linear elevation in the optical band gap has been revealed with an increase in the growth temperaturemediated network crystallinity (Fig. 10).

At $T_{\mathrm{S}}=150{ }^{\circ} \mathrm{C}$, the deviation in $\left(E_{\mathrm{g}}\right)_{\mathrm{PET}}$ from linearity is consistent with the similar deviation of $\left(\sigma_{\mathrm{D}}\right)_{\mathrm{PET}}$ and indicates the restriction of the substrate temperature with the use of the PET substrate, arising from its specific chemical nature. Furthermore, the difference in the magnitude of the estimated $E_{\mathrm{g}}$ of the two samples grown in the same run on glass and PET substrates may arise due to the change in the transparency of the PET substrate, which is different in chemical nature from glass, via plasma exposure at the early stage of film growth and that remaining unaccounted for in the process considering the reference substrate during optical measurements, thereby revealing a relatively narrower optical band gap (Fig. 10).

The electrical conductivity of the B-doped nc-Si films was found to have a direct one-to-one correlation with the network crystallinity. Under the investigated conditions, the crystalline volume fraction in the network grown on both flexible substrates (PP and PET) from the $\mathrm{SiH}_{4}$ plasma undiluted by additional $\mathrm{H}_{2}$ in ICP-CVD, follows a single straight-line relation, as shown in Fig. 10. At very high crystallinity, $\chi_{\mathrm{C}}>82.5 \%$, the p-nc-Si film deposited on PET at $T_{\mathrm{S}}>100{ }^{\circ} \mathrm{C}$ showed little deviation in the straight-line relation of $\sigma_{\mathrm{D}}$, which may arise because of the formation of surface cracks on the sample, hindering the usual transport of charge carriers across the network. In addition, the improved $\sigma_{\mathrm{D}}$ of the films on the glass substrate may occur due to the higher carrier density by virtue of increased dopant activation (Fig. 8) as an individual effect arising from the particular chemical nature of the substrate; ${ }^{50}$

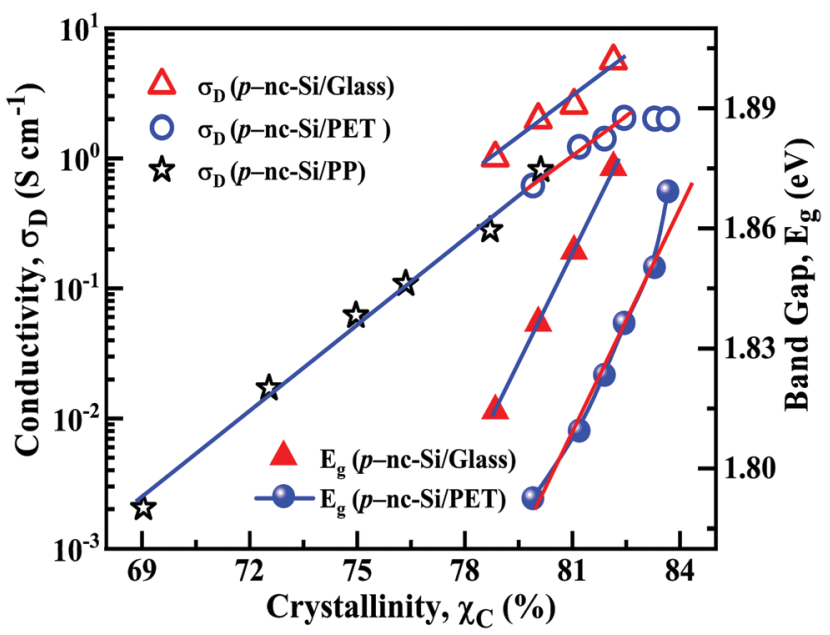

Fig. 10 Variation in the room temperature electrical conductivity of p-nc-Si films on glass, PP and PET substrates, demonstrating excellent systematic changes arising from the modification of crystallinity occurring with an increase in the growth temperature. The optical band gap of the films grown on glass and PET substrates showing individual linear widening with an increase in $T_{\mathrm{s}}$. 
however, a similar linear relation with identical slope between $\chi_{\mathrm{C}}$ and $\sigma_{\mathrm{D}}$ was maintained, as demonstrated in Fig. 10. The incorporation of an increased amount of dopant could result in increased distortion in the tiny host crystallites, and thereby, cause reduced crystallization in the network grown on the glass substrate than on PET substrate.

In the process of film growth by PECVD, the adsorption of the plasma precursors on the substrate, their temperaturemediated diffusion across the substrate surface, and finally sticking at some low energy site via the formation of chemical bonds with the substrate at an early stage are the different sequential steps involved. Therefore, in the elementary adsorption process, the chemical affinity between the substrate and the precursors plays a major role. The $\mathrm{SiH}_{\mathrm{n}}$ precursors easily form bonds with the similar Si element of the glass substrate via its abundant dangling bond, which results in a higher deposition rate compared to that on the PET substrate, where $\mathrm{C}$ is the major bonding element with various functional groups such as $-\mathrm{COOH},-\mathrm{OH}$, and $-\mathrm{C}=\mathrm{O} .{ }^{64}$ During the subsequent process, the evolution of the substrate surface roughness and creation of voids at the interface between the substrate and the incubation area of the growth zone, which is initiated by inhomogeneous etching of the weak $\mathrm{Si}-\mathrm{Si}$ bonds by atomic $\mathrm{H}$ of the plasma, result in structural reorientation and the formation of islands. These are the first set of nuclei, and nucleation becomes predominant for slower network formation during silicon nanocrystallization. ${ }^{65-67}$ In the early stage of growth of the nanocrystalline network, the deposition continues typically via the development of already existing nuclei because of the lower energy requirement, forming a columnar growth morphology. ${ }^{68,69}$ However, new nuclei are formed simultaneously, and the growth continues along the lateral dimension. Gradual coalescence of the columnar structures via lateral extension produces a compact and rigid network. Hence, the initial formation of nuclei controls the subsequent growth dynamics and determines the final network structure. This aspect highlights the importance of the substrate. The structural morphology and the chemical composition of the substrate, together with the growth parameters determine the nucleation, columnar configuration and amalgamation of the growth species. Thus, the better compliance via surface deformation on the flexible PET substrate compared to the rigid glass substrate affords intrinsic stress relaxation and promotes spontaneous crystallization in the Si network.

\section{Conclusion}

It was assessed that compared to the rigid glass, better compliance by means of deformation of the flexible polyethylene terephthalate (PET) substrate provides plausible intrinsic stress relaxation during the evolution of the film network via energy transfer across the film-substrate interface, which facilitates improved network crystallinity within a sustainable temperature limit up to $100{ }^{\circ} \mathrm{C}$. The inherent high electron density of the ICP-CVD provided surplus atomic $\mathrm{H}$ within the low pressure
$\mathrm{SiH}_{4}$ plasma without additional $\mathrm{H}_{2}$ dilution and the favorable strain-induced nanocrystallization kinetics at the incubation layer, arising from surface bending via plasma heating of the flexible PET substrate, which together promoted the high yield advanced crystallinity even at ambient temperature. The B-doped nc-Si films on PET substrate possessed high electrical conductivity and wide optical band gap by virtue of its functional dopability and high crystallinity, and exhibited the overall optoelectronic properties similar to that on glass substrates. The superior crystallinity $\left(\chi_{\mathrm{C}} \sim 82.5 \%\right)$ with an average grain size, $D_{\text {Raman }}$, of $\sim 9.63 \mathrm{~nm}$, wide band-gap, $E_{\mathrm{g}}$, of $\sim 1.836 \mathrm{eV}$ and high electrical conductivity, $\sigma_{\mathrm{D}}$, of $\sim 2.02 \mathrm{~S} \mathrm{~cm}^{-1}$ of the lowtemperature $\left(T_{\mathrm{S}}=100{ }^{\circ} \mathrm{C}\right)$ deposited B-doped nc-Si film on transparent and flexible PET substrate seem ideal for the window layer in nc-Si solar cells in the $\mathrm{p}-\mathrm{i}-\mathrm{n}$ superstrate configuration and also very suitable for application in low-cost flexible electronics. For large-scale device fabrication involving process automation, flexible polyethylene substrates are uniquely suitable, and the present work identifies an essential low temperature $\left(\sim 100{ }^{\circ} \mathrm{C}\right)$ avenue for the growth of device-grade p-nc-Si films via CMOS compatible plasma processing of $\mathrm{SiH}_{4}$ without deliberate $\mathrm{H}_{2}$ dilution using low-pressure, high-density, planar inductively coupled plasma.

\section{Author contributions}

The authors declare that they have equal contributions in this publication.

\section{Conflicts of interest}

The authors declare that they have no known competing financial interests or personal relationships that could have appeared to influence the work reported in this paper.

\section{Acknowledgements}

The work has been done under Nano-Silicon projects funded by the Department of Science and Technology (Nano-Mission Program) and the Council of Scientific and Industrial Research, Govt. of India. One author (C. P.) acknowledges DST, GoI, for providing INSPIRE Fellowship.

\section{References}

1 K. Nomura, H. Ohta, A. Takagi, T. Kamiya, M. Hirano and H. Hosono, Room-temperature fabrication of transparent flexible thin-film transistors using amorphous oxide semiconductors, Nature, 2004, 432, 488-492.

2 J. G. Lee, Y. G. Seol and N. E. Lee, Polymer thin film transistor with electroplated source and drain electrodes on a flexible substrate, Thin Solid Films, 2006, 515, 805-809.

3 A. Pecora, L. Maiolo, M. Cuscunà, D. Simeone, A. Minotti, L. Mariucci and G. Fortunato, Low-temperature polysilicon 
thin film transistors on polyimide substrates for electronics on plastic, Solid State Electron., 2008, 52, 348-352.

4 G. Qin, H. C. Yuan, H. Yang, W. Zhou and Z. Ma, Highperformance flexible thin-film transistor fabricated using print-transferrable polycrystalline silicon membranes on a plastic substrate, Semicond. Sci. Technol., 2011, 26, 025005-025010.

5 P. Y. Hsieh, C. Y. Lee and N. H. Tai, A high carrier-mobility crystalline silicon film directly grown on polyimide using $\mathrm{SiCl}_{4} / \mathrm{H}_{2}$ microwave plasma for flexible thin film transistors, J. Mater. Chem. C, 2015, 3, 7513.

6 N. Liu, K. N. Yun, H. Y. Yu, J. H. Shim and C. J. Lee, Highperformance carbon nanotube thin-film transistors on flexible paper substrates, Appl. Phys. Lett., 2015, 106, 103106.

7 S. M. Han, J. H. Park, S. G. Park, S. J. Kim and M. K. Han, Hydrogenation of nanocrystalline $\mathrm{Si}$ thin film transistors employing inductively coupled plasma chemical vapor deposition for flexible electronics, Thin Solid Films, 2007, 515, 7442-7445.

8 T. Sekitani, U. Zschieschang, H. Klauk and T. Someya, Flexible organic transistors and circuits with extreme bending stability, Nat. Mater., 2010, 9, 1015-1022.

9 X. Yu, L. Zeng, N. Zhou, P. Guo, F. Shi, D. B. Buchholz, Q. Ma, J. Yu, V. P. Dravid, R. P. H. Chang, M. Bedzyk, T. J. Marks and A. Facchetti, Ultra-flexible, "invisible" thin film transistors enabled by amorphous metal oxide/polymer channel layer blends, Adv. Mater., 2015, 27, 2390-2399.

10 A. Shah, P. Torres, R. Tscharner, N. Wyrsch and H. Keppner, Photovoltaic technology: the case for thin-film solar cells, Science, 1999, 285, 692-698.

11 F. Priolo, T. Gregorkiewicz, M. Galli and F. T. Krauss, Silicon nanostructures for photonics and photovoltaics, Nat. Nanotechnol., 2014, 9, 19-32.

12 H. Yamamoto, Y. Takaba, Y. Komatsu, M. J. Yang, T. Hayakawa, M. Shimizu and H. Takiguchi, High-efficiency $\mu \mathrm{c}-\mathrm{Si} / \mathrm{c}-\mathrm{Si}$ heterojunction solar cells, Sol. Energy Mater. Sol. Cells, 2002, 74, 525-531.

13 K. Tao, D. Zhang, Y. Sun, L. Wang, J. Zhao, Y. Xue, Y. Jiang, H. Cai, Y. Sui and J. Wang, $n-i-p$, Proc. of 4 th IEEE Int. Conf. on Nano/Micro Engineered and Molecular Systems, Shenzhen, China (2009), pp. 327-330.

14 Z. Huang, L. R. Dahal, M. M. Junda, P. Aryal, S. Marsillac, R. W. Collins and N. J. Podraza, Characterization of structure and growth evolution for nc-Si:H in the tandem photovoltaic device configuration, IEEE J. Photovoltaics, 2015, 5, 1516-1522.

15 J. K. Rath and R. E. I. Schropp, Incorporation of p-type microcrystalline silicon films in amorphous silicon based solar cells in a superstrate structure, Sol. Energy Mater. Sol. Cells, 1998, 53, 189-203.

16 T. Söderström, F. J. Haug, V. Terrazzoni-Daudrix and C. Ballif, Optimization of amorphous silicon thin film solar cells for flexible photovoltaics, J. Appl. Phys., 2008, 103, 114509.

17 L. Leopreknat, M. S. White, E. D. Głowacki, M. C. Scharber, T. Zillger, J. Rühling, A. Hübler and N. S. Sariciftci, $4 \%$ Efficient polymer solar cells on paper substrates, J. Phys. Chem. C, 2014, 118, 16813-16817.
18 K. Wilken, F. Finger and V. Smirnov, Annealing effects in low temperature amorphous silicon flexible solar cells, Energy Procedia, 2015, 84, 17-24.

19 S. Sriraman, S. Agrawal, E. S. Aydil and D. Maroudas, Mechanism of hydrogen-induced crystallization of amorphous silicon, Nature, 2002, 418, 62.

20 D. Das and M. Jana, Hydrogen plasma induced microcrystallization in layer-by-layer growth scheme, Sol. Energy Mater. Sol. Cells, 2004, 81, 169-181.

21 M. Kondo, Y. Nasuno, H. Mase, T. Wada and A. Matsuda, Low-temperature fabrication of microcrystalline silicon and its application to solar cells, J. Non-Cryst. Solids, 2012, 299302, 108-112.

22 D. Das, D. Raha, W. C. Chen, K. H. Chen, C. T. Wu and L. C. Chen, Effect of substrate bias on the promotion of nanocrystalline silicon growth from He-diluted $\mathrm{SiH}_{4}$ plasma at low temperature, J. Mater. Res., 2012, 27, 1303-1313.

23 C. Patra and D. Das, Electrically active boron doping in the core of Si nanocrystals by planar inductively coupled plasma CVD, J. Appl. Phys., 2019, 126, 155305.

24 D. Kar and D. Das, Conducting wide band gap nc-Si/a-SiC:H films for window layers in nc-Si solar cells, J. Mater. Chem. A, 2013, 1, 14744-14753.

25 C. Ossadnik, S. Veprek and I. Gregora, Applicability of Raman scattering for the characterization of nanocrystalline silicon, Thin Solid Films, 1999, 337, 148-151.

26 G. Zatryb, J. Misiewicz, P. R. J. Wilson, J. Wojcik, P. Mascher and A. Podhorodecki, Stress transition from compressive to tensile for silicon nanocrystals embedded in amorphous silica matrix, Thin Solid Films, 2014, 571, 18-22.

27 W. Wei, G. Xu, J. Wang and T. Wang, Raman spectra of intrinsic and doped hydrogenated nanocrystalline silicon films, Vacuum, 2007, 81, 656-662.

28 B. Hekmatshoar, D. Shahrjerdi, S. Mohajerzadeh, A. Khakifirooz, A. Goodarzi and M. Robertson, Low temperature crystallization of germanium on plastic by externally applied compressive stress, J. Vac. Sci. Technol., A, 2003, 21, 752.

29 S. Paydavosi, A. Ebrahimi, A. H. Tamaddon, S. Mohajerzadeh, N. Izadi, A. Behnam and M. D. Robertson, Hydrogenation assisted nickel-induced lateral nano-crystallization of amorphous silicon on flexible plastic substrates at low temperatures, Thin Solid Films, 2008, 516, 7790-7796.

30 D. Das and D. Kar, Self-assembled nc-Si-QD/a-SiC thin films from planar ICP-CVD plasma without $\mathrm{H}_{2}$-dilution: a combination of wide optical gap, high conductivity and preferred $\langle 220\rangle$ crystallographic orientation, uniquely appropriate for nc-Si solar cells, RSC Adv., 2016, 6, 3860-3869.

31 B. Sain and D. Das, Low temperature plasma processing of nc-Si/a-SiN ${ }_{x}: \mathrm{H}$ QD thin films with high carrier mobility and preferred (220) crystal orientation: a promising material for third generation solar cells, RSC Adv., 2014, 4, 36929-36939.

32 H. K. Malik, S. Juneja and S. Kumar, Employing constant photocurrent method for the study of defects in silicon thin flms, J. Theor. Appl. Phys., 2019, 13, 107-113.

33 D. Das and P. Mondal, Effect of oxygen on the optical, electrical and structural properties of mixed-phase boron 
doped nanocrystalline silicon oxide thin films, Appl. Surf. Sci., 2017, 423, 1161-1168.

34 Q. Cheng, S. Xu and K. Ostrikov, Rapid, low-temperature synthesis of nc-Si in high-density, non-equilibrium plasmas: enabling nanocrystallinity at very low hydrogen dilution, J. Mater. Chem., 2009, 19, 5134-5140.

35 D. Das and B. Sain, Rapid synthesis of nc-Si/a-SiN ${ }_{x}: H$ QD thin films by plasma processing for their cost effective applications in photonic and photovoltaic devices, $R S C$ Adv., 2015, 5, 63572.

36 D. Das and A. Samanta, Quantum size effects on the optical properties of nc-Si QDs embedded in an $\mathrm{a}^{-\mathrm{SiO}_{x}}$ matrix synthesized by spontaneous plasma processing, Phys. Chem. Chem. Phys., 2015, 17, 5063.

37 C. J. Fang, K. J. Gruntz, L. Ley, M. Cardona, F. J. Demond, G. Muller and S. Kalbitzer, The hydrogen content of a-Ge:H and aSi:H as determined by IR spectroscopy gas evolution and nuclear reaction techniques, J. Non-Cryst. Solids, 1980, 35-36, 255-260.

38 S. Samanta and D. Das, Nanocrystalline silicon thin films from $\mathrm{SiH}_{4}$ plasma diluted by $\mathrm{H}_{2}$ and $\mathrm{He}$ in RF-PECVD, J. Phys. Chem. Solids, 2017, 105, 90-98.

39 A. Fontcuberta i Morral and P. Roca i Cabarrocas, Etching and hydrogen diffusion mechanisms during a hydrogen plasma treatment of silicon thin films, J. Non-Cryst. Solids, 2002, 299-302, 196-200.

40 J. Liu, Y. Zhang, Z. Fan, H. Sun and F. Shan, Low-temperature deposition of large-grain polycrystalline Si thin films on polyethylene terephthalate, Thin Solid Films, 2020, 707, 138065.

41 E. A. T. Dirani, A. M. Andrade, L. K. Noda, F. J. Fonseca and P. S. Santos, Effect of the substrate on the structural properties of low temperature microcrystalline silicon films - A Raman spectroscopy and atomic force microscopy investigation, J. Non-Cryst. Solids, 2000, 273, 307-313.

42 R. J. Swanepoel, Determination of the thickness and optical constants of amorphous silicon, J. Phys. E: Sci. Instrum., 1980, 16, 1214.

43 J. Tauc, R. Grigorovici and A. Vancu, Optical properties and electronic structure of amorphous germanium, Phys. Status Solidi B, 1966, 15, 627.

44 B. Sain and D. Das, Development of nc-Si/a-SiN$x: H$ thin films for photovoltaic and light-emitting applications, Sci. Adv. Mater., 2013, 5, 1-11.

45 D. Das and B. Sain, Electrical transport phenomena prevailing in undoped nc-Si/a-SiN $\mathrm{S}_{x}: \mathrm{H}$ thin films prepared by inductively coupled plasma chemical vapor deposition, J. Appl. Phys., 2013, 114, 073708.

46 B. M. Monroy, G. Santana, J. Fandiño, A. Ortiz and J. C. Alonso, Growth of silicon nanoclusters on different substrates by plasma enhanced chemical vapor deposition, J. Nanosci. Nanotechnol., 2006, 6, 3752-3755.

47 C. Song, J. Xu, G. Chen, H. Sun, Y. Liu, W. Li, L. Xu, Z. Ma and K. Chen, High-conductive nanocrystalline silicon with phosphorous and boron doping, Appl. Surf. Sci., 2010, 257, 1337-1341.

48 M. Kondo, Y. Toyoshima, A. Matsuda and K. Ikuta, Substrate dependence of initial growth of microcrystalline silicon in plasma-enhanced chemical vapor deposition, J. Appl. Phys., 1996, 80, 6061.

49 D. Ma, J. Liu and W. Zhang, The effect of negative bias on the preparation conditions and structural changes in borondoped nanocrystalline silicon thin films prepared on PET, J. Non. Cryst. Solids, 2017, 475, 53-58.

50 P. Alpuim, V. Chu and J. P. Conde, Doping of amorphous and microcrystalline silicon films deposited at low substrate temperatures by hot-wire chemical vapor deposition, J. Vac. Sci. Technol., A, 2001, 19, 2328.

$51 \mathrm{~J}$. H. Lee, Influence of substrates on the structural and optical properties of chemically deposited CdS films, Thin Solid Films, 2007, 515, 6089-6093.

52 M. G. Faraj, K. Ibrahim, M. H. Eisa, M. K. M. Pakhuruddin and M. Z. Pakhuruddin, Comparison of zinc oxide thin films deposited on the glass and polyethylene terephthalate substrates by thermal evaporation technique for applications in solar cells, Optoelectron. Adv. Mater., Rapid Commun., 2010, 4, 1587-1590.

53 A. N. Banerjee, C. K. Ghosh, K. K. Chattopadhyay, H. Minoura, A. K. Sarkar, A. Akiba, A. Kamiya and T. Endo, Low-temperature deposition of ZnO thin films on PET and glass substrates by DC-sputtering technique, Thin Solid Films, 2006, 496, 112-116.

54 R. Mohammadigharehbagh, S. Pat, S. Özen, H. H. Yudar and S. Korkmaz, Investigation of the optical properties of the indium-doped $\mathrm{ZnO}$ thin films deposited by a thermionic vacuum arc, Optik, 2018, 157, 667-674.

55 H. L. Shen, H. Zhang, L. F. Lu, F. Jiang and C. Yang, Preparation and properties of AZO thin films on different substrates, Prog. Nat. Sci.: Mater. Int., 2010, 20, 44-48.

56 M. P. Manoharan, S. Kumar, M. A. Haque, R. Rajagopalan and H. C. Foley, Room temperature amorphous to nanocrystalline transformation in ultra-thin films under tensile stress: an in situ TEM study, Nanotechnology, 2010, 21, 505707.

57 B. J. Lee, C. S. Lee and J. C. Lee, Stress induced crystallization of amorphous materials and mechanical properties of nanocrystalline materials: a molecular dynamics simulation study, Acta Mater., 2003, 51, 6233-6240.

58 B. Hekmatshoar, S. Mohajerzadeh and D. Shahrjerdi, Thinfilm tunneling transistors on flexible plastic substrates based on stress-assisted lateral growth of polycrystalline germanium, Appl. Phys. Lett., 2004, 85, 1054.

59 K. Bhattacharya and D. Das, Effect of deposition temperature on the growth of nanocrystalline silicon network from helium diluted silane plasma, J. Phys. D: Appl. Phys., 2008, 41, 155420.

60 D. Das, Rigid amorphous silicon network from hydrogenated and fluorinated precursors in ECR-CVD, Sol. Energy Mater. Sol. Cells, 2004, 81, 155-168.

61 D. Das, Wide band gap Si:H at low H-content prepared by interrupted growth and H-plasma treatment, Jpn. J. Appl. Phys., 1994, 33, L571-L574.

62 D. Das, A novel approach towards silicon nanotechnology, J. Phys. D: Appl. Phys., 2003, 36, 2335-2346. 
63 A. H. Mahan, R. Biswas, L. M. Gedvilas, D. L. Williamson and B. C. Pan, On the influence of short and medium range order on the material band gap in hydrogenated amorphous silicon, J. Appl. Phys., 2004, 96, 3818-3826.

64 L. Kinner, M. Bauch, R. A. Wibowo, G. Ligorio, E. J. W. ListKratochvil and T. Dimopoulos, Polymer interlayers on flexible PET substrates enabling ultra-high performance, ITO-free dielectric/metal/dielectric transparent electrode, Mater. Des., 2019, 168, 107663.

65 D. Das, Plasma kinetics, surface phenomena and growth mechanism in hydrogenated amorphous silicon: Transition from amorphous to micro- and nano-crystalline $\mathrm{Si}: \mathrm{H}$, in Solid State Phenomena (Special Volume on Hydrogenated Amorphous Silicon), Scitec Publication, Switzerland, 1995, vol. 44-46, pp. 227-258.
66 P. Roca i Cabarrocas, N. Layadi, B. Drevillon and I. Solomon, Microcrystalline silicon growth by the layer-by-layer technique: long term evolution and nucleation mechanisms, J. NonCryst. Solids, 1996, 198-200, 871-874.

67 D. Raha and D. Das, Hydrogen induced promotion of nanocrystallization from He-diluted $\mathrm{SiH}_{4}$ plasma, J. Phys. D: Appl. Phys., 2008, 41, 085303.

68 H. Shirai, B. Drevillon and I. Shimizu, Role of hydrogen plasma during growth of hydrogenated microcrystalline silicon: in situ UV-visible and infrared ellipsometry study, Jpn. J. Appl. Phys., 1994, 33, 5590.

69 M. Jana, D. Das, S. T. Kshirsagar and A. K. Barua, Control of crystallization at low thickness in $\mu \mathrm{c}-\mathrm{Si}: \mathrm{H}$ films using layerby-layer growth scheme, Jpn. J. Appl. Phys., 1999, 38, L1087-L1090. 